\title{
Pelatihan Pembuatan Video Animasi Pembelajaran Menggunakan Microsoft Powerpoint Pada Rumah Baca Asmanadia Sumbang
}

\author{
Afika Kurnia Dewi, Aktri Tohaningrum, Nur Minda Widi Maylenasari
}

\author{
Sistem Informasi \\ Universitas Nusa Mandiri, Jl. Kramat Raya No.18, RW.7, Kwitang, Kec. Senen, Kota \\ Jakarta Pusat, Daerah Khusus Ibukota Jakarta 10450
}

Email: afikakurniadewi08@gmail.com, aktritohaningrum.01ap3@gmail.com, widinurminda@gmail.com

\begin{abstract}
Abstrak
Perkembangan teknologi telah membawa berbagai perubahan terutama dalam dunia pendidikan. Microsoft Power Point merupakan aplikasi yang dapat mempermudah membuat materi presentasi. Fitur yang terdapat dalam Microsoft Power Point sangatlah beragam, misalnya dalam pembuatan video animasi. Pelatihan dengan menggunakan Media Microsoft Power Point dapat meningkatkan kreativitas dan dapat menambah wawasan kepada siswa di Rumah baca Asmanadia Sumbang Siswa dapat mengembangkan kreativitasnya dalam berkarya membuat animasi pembelajaran dengan menggunakan aplikasi Microsoft Power Point. Permasalahan di Ruang Baca Asma Nadia dimana beberapa siswa gagal menguasai Microsoft Power Point. Karena kurangnya pengetahuan saya tentang Microsoft Power Point dan terbatasnya waktu untuk guru Rumah Baca Asma Nadia.Dibutuhkan kreativitas untuk membuat animasi yang menarik. Pelatihan dan pembuatan materi pembelajaran sangatlah penting bertujuan agar siswa dapat meningkatkan ketrampilan mereka di bidang pembuatan video animasi. Siswa mendapatkan pengetahuan mengenai penggunaan Microsoft power point maupun tools yang terdapat didalamnya yang dapat digunakan sebagai media interaktif. Kegiatan ini dapat memotivasi siswa khususnya siswa sekolah dasar untuk menggunakan program-program dalam komputer sebagai media pembelajaran.
\end{abstract}

Kata Kunci:Microsoft Power Point, Video Animasi, Media Pembelajaran, Siswa, Pelatihan.

\section{Pendahuluan}

Pesatnya perkembangan teknologi telah membawa berbagai perubahan terutama dalam bidang dunia pendidikan. Bidang pendidikan merupakan salah satu bidang yang sangat dipengaruhi oleh teknologi informasi, baik dalam proses pembelajaran formal di sekolah maupun nonformal berupa pelatihan di luar sekolah. Dengan menggunakan Teknologi Informasi dan Komunikasi, suatu proses dan kegiatan dapat dilakukan dengan cepat, mudah dan efisien (Dharmawati 2020).

Contoh khusus dapat kita lihat adalah proses pendidikan yang dilakukan oleh guru, yang sebagian besar menggunakan teknologi sebagai alat pendidikan, sehingga dengan kemajuan teknologi seperti ini diperlukan suatu badan kerjasama yang bertujuan untuk memajukan kualitas mengajar. Permasalahan di Ruang Baca Asma Nadia dimana beberapa siswa gagal menguasai Microsoft Power Point. Karena kurangnya pengetahuan tentang Microsoft Power Point dan terbatasnya waktu untuk guru Rumah Baca Asma Nadia, tidak dapat dengan cepat mempelajari cara menggunakan Microsoft Power Point. Rumah Baca Asma Nadia Sumbang, rumah baca ini didirikan bukan hanya untuk meningkatkan minat baca anak tapi juga untuk meningkatkan karakter anakanak. Tak cukup sampai pada taraf pintar, anak-anak juga harus mempunyai sikap dan mental yang baik. Maka kegiatan di Rumah Baca Asma Nadia tidak hanya difokuskan pada kegiatan membaca saja tapi juga ada beragam kegiatan lain untuk mengasah kecerdasan karakter anak- anak misalnya kelas kreasi, games, memasak, Taman Pendidikan Qur'an, peduli lingkungan, dan baksos.(Nurisusilawati 2019). Pada era sekarang ini sangat penting adanya media pembelajaran, media pembelajaran terdiri dari dua kata, yaitu kata "media" dan "pembelajaran". Kata media secara 
harfiah berarti perantara atau pengantar, sedangkan kata pembelajaran diartikan sebagai kondisi untuk membantu seseorang melakukan status kegiatan belajar. Dari definisi yang telah dikemukakan tersebut maka dapat disimpulkan bahwa pengertian media pembelajaran adalah segala sesuatu yang dapat digunakan untuk menyalurkan pesan (bahan pembelajaran), sehingga dapat merangsang perhatian, minat, pikiran, dan perasaan siswa dalam kegiatan belajar untuk mencapai tujuan belajar (Arsyad 2011). Tanpa sistem komputer, pembelajaran akan terasa monoton. Dengan bantuan sistem yang terkomputerisasi informasi dapat dikelola dengan baik, sehingga dapat menciptakan efisien biaya dan waktu. Melihat perkembangan teknologi yang semakin pesat, masyarakat harus bisa mengikuti perkembangan itu sendiri. Salah satu alternatif pilihan adalah media pembelajaran interaktif berbasis komputer sebagai bentuk media pembelajaran yang mampu mengkongkretkan materi yang bersifat abstrak serta adaftif dengan perkembangan teknologi informasi dan komunikasi. Kehadiran media dalam pembelajaran juga dikatakan dapat membantu peningkatan pemahaman siswa, penyajian data/informasi lebih menarik dan terpercaya, memudahkan penafsiran data, dan memadatkan informasi. Jadi dalam hal ini dikatakan bahwa fungsi media adalah sebagai alat bantu dalam proses pembelajaran (Yanto 2019). Semua aspek kegiatan pasti di kerjakan menggunakan teknologi. Microsoft powerpoint merupakan salah satu program berbasis multimedia. Software ini, menyediakan fasilitas dalam bentuk slide-slide yang dapat membantu dalam menyusun suatu presentasi yang efektif, professional, dan juga mudah. Sehingga memungkinkan para guru sekolah untuk memanfaatkan sebagai media pembelajaran banyak perangkat lunak berasal kemajuan teknologi yang berfungsi untuk memudahkan pekerjaan (Parnabhakti, Puspaningtyas, and Indonesia 2021) Menggunakan perkembangan teknologi akan memudahkan kita pada pengolahan data yang dapat menghemat waktu serta biaya. Melihat perkembangan teknologi yang semakin pesat, masyarakat harus bisa mengikuti perkembangan itu sendiri. Pendekatan teknologi pendidikan, media pengajaran menjadi daya tarik bagi dunia pendidikan, ia tidak hanya notabennya sebagai alat bantu, akan tetapi juga sebagai alat penyalur pesan pesan pendidikan. Walaupun tanpa bantuan guru, media pendidikan dapat menghadapi siswa dalam belajar di kelas. Penggunaan media pendidikan dapat membantu guru dalam menyampaikan materi agar lebih praktis. Selain itu penggunaan media pembelajaran dapat merangsang pola pikir siswa, dan sebagai upaya pengembangan dalam proses belajar mengajar agar lebih variatif. metode yang menggunakan media visual dalam hal ini adalah Microsoft PowerPoint. Metode ini digunakan oleh pengajar dalam rangka agar peserta didik lebih memahami pelajaran dalam suasana yang menyenangkan dan menarik (Muthoharoh 2019).Seluruh aspek kegiatan pasti di kerjakan menggunakan teknologi. banyak aplikasi berasal kemajuan teknologi yang berfungsi buat memudahkan pekerjaan. Hanya dengan menaikkan kreatifitas untuk memodifikasi aktivitas tersebut agar lebih menarik.

\subsection{Tujuan Kegiatan}

Tujuan kegiatan ini adalah untuk melatih para siswa membuat animasi menggunakan Microsoft power point di Rumah Baca Asmanadia Sumbang sehingga mampu meningkatkan minat belajar siswa dalam membuat animasi untuk meningkatkan minat belajar anak.

\subsection{Manfaat Kegiatan}

Manfaat yang diharapkan dari pelatihan ini adalah Media Microsoft Power Point dapat meningkatkan kreativitas dan dapat menambah wawasan kepada siswa di Rumah baca Asmanadia Sumbang Siswa dapat mengembangkan kreativitasnya dalam berkarya membuat animasi pembelajaran dengan menggunakan aplikasi Microsoft Power Point

\subsection{Luaran Pengabdian Kepada Masyarakat}

Target Luaran dalam kegiatan pengabdian kepada masyarakat ini, yaitu:

a. Berupa beberapa buku yang akan disumbangkan di Rumah Baca Asmanadia Sumbang.

b. Siswa mampu mengoperasikan Microsoft Powerpoint.

c. Siswa mampu membuat video animasi menggunakan Microsoft Power Point

\section{Realisasi Kegiatan}

\subsection{Bentuk Kegiatan \& Jadwal, Serta Tempat Kegiatan \\ a. Metode Pelaksanaan Kegiatan}

Pelatihan Pembuatan Video Animasi Pembelajaran Menggunakan Microsoft Powerpoint Pada Rumah Baca Asmanadia Sumbang... (Afika Kurnia Dewi, dkk) 
Pelatihan Microsoft Power Point untuk siswa di "Rumah Baca Asmanadia Sumbang" dilaksanakan dengan metode ceramah, diskusi dan praktik. Metode Ceramah dilakukan dengan memberikan penjelasan mengenai Microsoft Power Point. Pada metode kedua yaitu metode diskusi dilakukan dengan memberikan waktu bila ada pertanyaan atau tanggapan dari siswa. Metode ketiga yaitu metode praktik yaitu para siswa langsung praktik di komputer yang sudah disediakan sesuai dengan yang di jelaskan sebelumnya, sambil instruktur mengamati dan memberikan arahan praktik para siswa tersebut. Proses pelatihan dilaksanakan selama 2 sesi , untuk sesi 1 pada jam 08.3010.00, untuk sesi ke 2 pada jam 10.00-11.30 masing-masing selama 1.5 jam. Selama proses pelatihan, peserta diberikan modul atau buku tutorial pelatihan yang dipakai untuk acuan pelatihan.

b. Waktu Efektif Pelaksanaan Kegiatan

Kegiatan Pelaksanaan Pengabdian Kepada Masyarakat ini akan dilaksanakan pada Tanggal 19 Desember 2021 dengan rincian sebagai berikut:

Tabel 1. Jadwal Pelaksanaan

\begin{tabular}{|c|l|c|c|}
\hline \multirow{2}{*}{ NO } & \multicolumn{1}{|c|}{ Kegiatan } & Jadwal Pelaksanaan Tanggal : \\
\cline { 3 - 4 } & \multicolumn{1}{|c|}{$\mathbf{1 8}$} & $\mathbf{1 9}$ \\
\hline 1 & Persiapan Peralatan & & \\
\hline 2 & Pengantaran Materi Presentasi Materi & \\
\hline 3 & Latihan & \\
\hline
\end{tabular}

\section{c. Tempat Kegiatan}

Tempat pelaksanaan pengabdian kepada masyarakat ini beralamatkan di desa Tambaksogra RT 03 RW 01 kecamatan Sumbang.
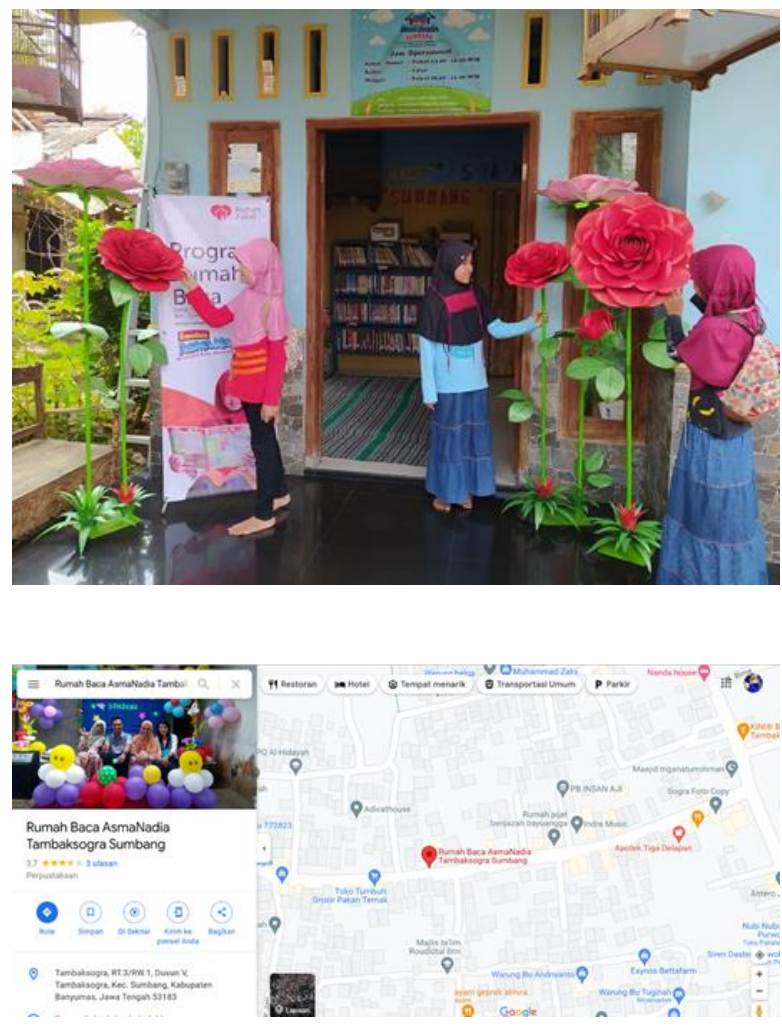

Gambar 2. Lokasi Pengabdian

\subsection{TIM Pelaksana Pengabdian dan TUPOKSI serta (Jam dan hari)} a. Susunan TIM Pengabdian 


\begin{tabular}{|l|l|l|l|}
\hline No & \multicolumn{1}{|c|}{ Peran dalam TIM } & \multicolumn{1}{|c|}{$\begin{array}{c}\text { Tanggung jawab } \\
\text { dalam TIM }\end{array}$} & Dosen/Mahasiswa \\
\hline 1 & Afika Kurnia Dewi & Anggota Pengabdi & Mahasiswa \\
\hline 2 & Aktri Tohaningrum & Anggota Pengabdi & Mahasiswa \\
\hline 3 & $\begin{array}{l}\text { Nur Minda Widi } \\
\text { Maylenasari }\end{array}$ & Anggota Pengabdi & Mahasiswa \\
\hline
\end{tabular}

\section{b. Tugas Pokok serta Peran setiap TIM Pengabdian}

\begin{tabular}{|c|c|c|c|c|}
\hline No & Nama Pekerjaan & Program & Volume (JKEM) & Pemateri \\
\hline \multicolumn{5}{|c|}{ HARI Pertama Tanggal 18 Desember 2021} \\
\hline 1 & $\begin{array}{ll}\text { - } & \text { Persiapan Alat } \\
\text { - } & \text { Persiapan } \\
& \text { Hardware dan } \\
& \text { Software }\end{array}$ & $\begin{array}{l}\text { - Mempersiapkan alat } \\
\text { - Mempersiapkan kesiapan } \\
\text { hardware dan software }\end{array}$ & 08:30 s.d 11.00 Wib & $\begin{array}{l}\text { Afika Kurnia Dewi } \\
\text { Aktri Tohaningrum }\end{array}$ \\
\hline \multicolumn{5}{|c|}{ HARI Kedua 19 Desember 2021} \\
\hline 2 & $\begin{array}{l}\text { - Pengenalan } \\
\text { Microsoft Power } \\
\text { Point } \\
\text { - Memulai membuat } \\
\text { video animasi } \\
\text { - Mengolah video } \\
\text { animasi }\end{array}$ & $\begin{array}{l}\text { - Pengetahuan dasar mengenai } \\
\text { Microsoft PowerPoint beserta } \\
\text { kegunaannya } \\
\text { - Memandu membuat video } \\
\text { animasi } \\
\text { - Memulai membuat vdeo animasi } \\
\text { - Menambahkan gambar, animasi } \\
\text { dll } \\
\text { - Mengolah video Animasi menjadi } \\
\text { format MP4 }\end{array}$ & 08:30 s.d $11.30 \mathrm{Wib}$ & $\begin{array}{l}\text { Afika Kurnia Dewi } \\
\text { Aktri Tohaningrum } \\
\text { Nur Minda Widi } \\
\text { Maylenasari }\end{array}$ \\
\hline
\end{tabular}

\subsection{Ringkasan/Garis-garis besar Materi}

Power point merupakan salah satu dari program microsoft (MS) office dan merupakan salah satu software yang dirancang khusus untuk mampu menampilkan program multimedia dengan menarik, mudah dalam pembuatan, mudah dalam penggunaan dan relatif murah, karena tidak membutuhkan bahan baku selain alat untuk penyimpanan data (data storage). Kelebihan Power Point antara lain: dapat menyajikan teks, gambar, film, sound efek, lagu, grafik, dan animasi sehingga menimbulkan pengertian dan ingatan yang kuat, mudah direvisi, mudah disimpan dan efisien, dapat dipakai berulang-ulang, dapat diperbanyak dalam waktu singkat dan tanpa biaya, dapat dikoneksikan dengan internet (Adhi, Nurseto 2018).

Secara garis besar apa yang dikerjakan di power point meliputi:

a) Membuka program Power Point

Microsoft Power Point dapat dilihat melalui berbagai cara. Microsoft power point langsung terlihat pada halaman depan yang disebut dengan short cut, untuk membuka program power point dapat langsung klik short cut tersebut. Jika di layar utama windows nama power point tidak terlihat, dapat dilakukan dengan cara search pada bagian kiri bawah dengan mengetikkan PowerPoint maka akan muncul aplikasi dan segera bisa digunakan.

b) Mereset Bakground

Jika power point pada halaman utama sudah siap dan berwarna putih pada awalnya dengan model layout yang telah ditentukan, maka selanjutnya adalah mereset atau mengganti background dengan cara format bakground dan memilih pada gambar yang sudah tersedia pada computer.

c) Pengaturan tampilan

d) Menambahkan gambar animasi dengan format GIF

e) Pengaturan letak gambar

f) Mengatur dan menambahkan efek animasi, serta teks pada gambar

g) Penyajian tampilan

h) Mengolah video animasi menjadi format MP4 


\subsection{Masyarakat Sasaran}

Seluruh Siswa Rumah Baca Asmanadia Sumbang total yang mengikuti pelatihan ini adalah sebanyak 20 orang siswa.

\section{Tinjauan Hasil Yang Dicapai}

Adanya pengabdian masyarakat ini pelatihan pembuatan Animasi menggunakan menggunakan Microsoft PowerPoint untuk siswa di Rumah Baca Asmanadia Sumbang telah berlangsung dengan baik. Hal ini terlihat dari siswa yang sangat senang dan bersemangat mengikuti pelatihan pembuatan animasi menggunakan microsofot powerpoint, diharapkan siswa dapat mempermudah siswa dalam proses belajar mengajar dan memahami media pembelajaran sebagai alat pembelajaran lebih menarik dibandingkan dengan menggunakan cara manual yang masih umum digunakan sampai sekarang. Siswa pelatihan menunjukkan minat terhadap materi pelatihan yang diberikan.

Sesuai dengan harapan para orang tua dan pengajar di Rumah Baca Asmanadia Sumbang, mereka sangat mengharapkan adanya kegitan-kegiatan yang sifatnya memberi penyegaran bagi para siswa di daerah ini, baik terkait dengan pendalaman materi bidang studi ataupun terkait dengan metode mengajar dan media pembelajaran, kegiatan pengabdian ini telah berlangsung dengan baik.

Sehingga dapat disimpulkan Media PowerPoint dapat meningkatkan kreativitas dan dapat menambah wawasan pada siswa, dengan diadakannya pelatihan ini dapat bermanfaat bagi para pengajar dan siswa, dan menggunakan PowerPoint untuk membuat materi pelatihan pembelajaran interaktif, kegiatan ini dapat memotivasi siswa khususnya siswa sekolah dasar untuk menggunakan program-program dalam komputer sebagai media pembelajaran, siswa dapat mengembangkan kreativitasnya dalam berkarya membuat animasi pembelajaran dengan menggunakan aplikasi microsoft powerpoint.

\section{Daftar Pustaka}

Adhi, Nurseto, 2012. 2018. "Pengaruh Karakteristik Perusahaan Terhadap Luas Pengungkapan Sukarela Dan Implikasinya Terhadap Asimetri Informasi (Studi Pada Perusahaan Manufaktur Yang Terdaftar Di Bursa Efek Indonesia Tahun 2009). Skripsi. Semarang : Program Studi Akuntansi Universita." 30(02):106-26.

Arsyad, Azhar. 2011. 2011. Media Pembelajaran. Jakarta: PT. Raja Grafindo Persada.

Dharmawati, Dharmawati. 2020. "Pembelajaran Berbasis Komputer Menggunakan Ms. Office 2019 Pada Siswa Di Smk Dwitunggal 1 Tanjung Morawa." Dinamisia : Jurnal Pengabdian Kepada Masyarakat 4(1). doi: 10.31849/dinamisia.v4i1.3751.

Muthoharoh, Miftakhul. 2019. "Media PowerPoint Dalam Pembelajaran." 2(April):21-32.

Nurisusilawati, Isnaini-. 2019. "Strategi Pengembangan Rumah Baca Asma Nadia Sumbang." JPM17: Jurnal Pengabdian Masyarakat 4(2):67-73. doi: 10.30996/jpm17.v4i2.2369.

Parnabhakti, Lily, Nicky Dwi Puspaningtyas, and Universitas Teknokrat Indonesia. 2021. "PERSEPSI PESERTA DIDIK PADA MEDIA POWERPOINT." 2(1):18-25.

Yanto, Doni Tri Putra. 2019. "Praktikalitas Media Pembelajaran Interaktif Pada Proses Pembelajaran Rangkaian Listrik." INVOTEK: Jurnal Inovasi Vokasional Dan Teknologi 19(1):75-82. doi: 10.24036/invotek.v19i1.409. 


\section{Daftar Hadir}

\section{Daftar Hadir Peserta sebagai berikut:}

\section{DAFTAR HADIR PESERTA PENGABDIAN MASYARAKAT DI RUMAH BACA ASMANADIA SUMBANG}

\begin{tabular}{|c|c|c|c|c|}
\hline No & NAMA & KE.L.AS & KETERANGAN & TANDA TANGAN \\
\hline 1 & AZKKA & 5 & \multirow{10}{*}{$\begin{array}{c}\text { KEIOMPOK I } \\
\text { PUKUL 08.30 s d } \\
09.30 \text { WIB }\end{array}$} & 1 Nhat \\
\hline 2 & ARUL & 5 & & $2 \mathrm{Ko}$ \\
\hline 3 & GEVIN & 5 & & 3 ges \\
\hline 4 & RAFHKA & 5 & & 4 Bes \\
\hline 5 & NANDO & 6 & & $5 \mathrm{Nul}$ \\
\hline 6 & RAFA & 6 & & 602 \\
\hline 7 & REHAN & 6 & & $7 \mathrm{QQ}$ \\
\hline 8 & FADLI & 6 & & \multirow{2}{*}{ 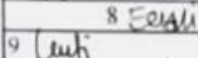 } \\
\hline 9 & LUTHI & 6 & & \\
\hline 10 & HELGA & 5 & & 10 मान \\
\hline 11 & NIA & 5 & \multirow{11}{*}{$\begin{array}{l}\text { KELOMPOK } 2 \\
\text { PUKUI. } 09.30 \mathrm{~s} \mathrm{~d} \\
10.30 \text { WIB }\end{array}$} & 11 2hy \\
\hline 12 & OLIV & 5 & & $12 a+9$ \\
\hline 13 & DHIIFA & 5 & & 13 Thiler \\
\hline 14 & DEA & 5 & & $14 \mathrm{Qul}$ \\
\hline 15 & DHIIL.A & 5 & & \multirow{3}{*}{$\begin{array}{l}15 \mathrm{FPn} \\
17 \mathrm{AL} \\
\end{array}$} \\
\hline 16 & AULIA & 5 & & \\
\hline 17 & NINDY & 5 & & \\
\hline 18 & RENATA & 6 & & \multirow{2}{*}{$\frac{18 \mathrm{pg}}{19 \mathrm{Dg}}$} \\
\hline 19 & DHIILA & 6 & & \\
\hline 20 & KESHYA & 6 & & 19 Dset $20 \mathrm{w/2}$ \\
\hline 21 & SIVA & 6 & & $21 \mathrm{sy}$ \\
\hline
\end{tabular}

Purwokerto, 19 Desember 2021

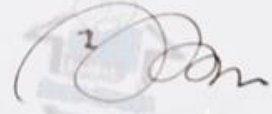

Fatiah Fidiyanti

Ketua Rumah Baca AsmaNadia 


\section{Surat Keterangan}

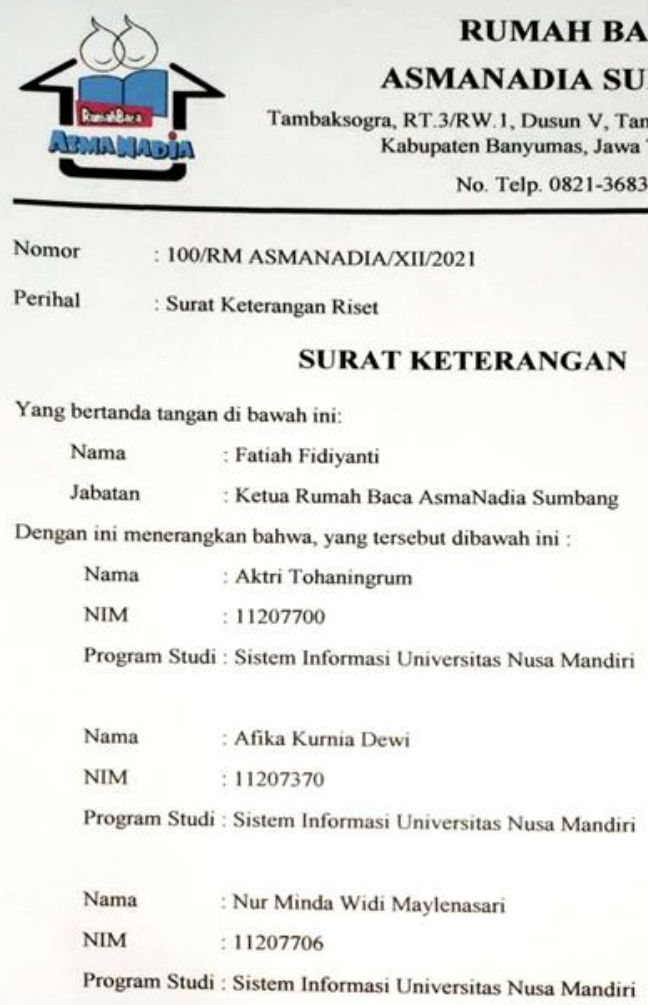

Adalah benar telah melakukan riset pada Rumah Baca AsmaNadia Sumbang pada 19 Desember 2021, dan yang bersangkutan telah melaksanakan tugasnya dengan baik dan penuh tanggung jawab.

Demikian surat keterangan ini dibuat dengan benar, untuk dapat dipergunakan sebagaimana mestinya.

Purwokerto, 19 Desember 2021

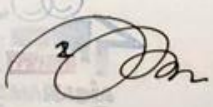

Fatiah Fidiyanti

Ketua Rumah Baca AsmaNadia 


\section{Foto Foto Kegiatan}
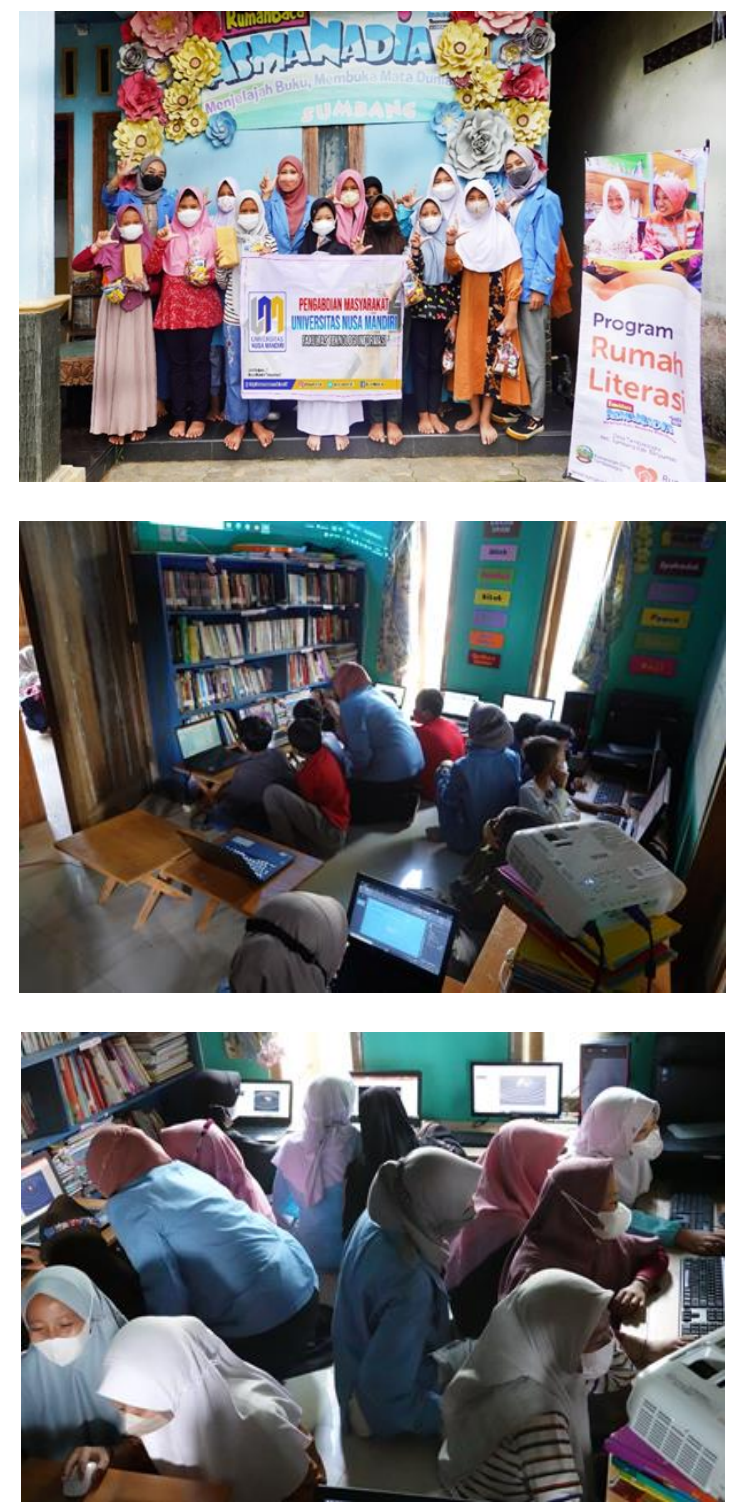